\title{
University Students' Beliefs on Communicating Meanings: Justifying the Language Policy
}

\author{
Joseph Kimoga \\ East African School of Higher Education Studies and Development, College of Education, \\ Makerere University, Kampala, Uganda \\ Email: kimogaj@yahoo.com
}

Received 3 March 2014; revised 5 April 2014; accepted 14 April 2014

Copyright (C) 2014 by author and Scientific Research Publishing Inc. This work is licensed under the Creative Commons Attribution International License (CC BY). http://creativecommons.org/licenses/by/4.0/ c) (i) Open Access

\begin{abstract}
Language is about passing on meanings. This implies a speaker's level of proficiency and fluency and a level of comprehension by the listener. English, a widely used medium, has been deeply researched on in how it is used by non-native speakers to inform native speakers, and by native speakers to inform non-native speakers. However, little research is done on non-native speakers using it to inform non-native speakers. This article draws on the research done with university students carrying out their practicum using English as the medium suggested in the government policy. Their voices indicate that despite their limited proficiency and fluency, linguistic choices are based on their beliefs. Therefore, utterances should not be judged on the basis of proficiency and fluency but on beliefs which are shaped by their culture, policies and interactive situation.
\end{abstract}

\section{Keywords}

Beliefs, Practice, Language Policy, Open Questions, Closed Questions, Chorus Answer Questions

\section{Introduction}

Language can either be understood as a code or as a tool used to make meaning. Language acquires dynamism when used to communicate meanings between parties. As a code it identifies a strong or loose belongingness to a community. This is because a native can claim it as their first medium of interaction whereas a non-native associates themselves with it.

English, in particular, as noted by Laoire (2012) is a language of prestige which is internationally used for "upward mobility" because it opens opportunities to employability. As a code it has natives who take it as their 
first language for communication. And as an international language, many non-natives associate themselves with it in their social, economic, political, and academic encounters. Limitedness in proficiency and literacy skills in English may be a barrier to mobility (Batalova \& Fix, 2010). In order to acquire a language, Taboada and Rutherford (2011) affirm that one has to learn a wider variety of vocabulary, word classes, syntax, phonemes, and inflections as well as the language's social-cognitive dimensions. Despite being widely a favourite to many nonnatives, it could be one of the languages where native users hardly tolerate those who "cannot speak with an accent" i.e. phonologically, syntactically, etc.

In the last decade, much literature has focused on how English is perfected among the natives and the nonnatives living in situations where English is the first language. English Language Teaching (ELT) as a code to native users has attracted research attention (Helfrich \& Bosh, 2011; Pettit, 2011; Baurain, 2011; Nag \& Snowling, 2012; Peercy, 2011; Taboada \& Rutherford, 2011; Seedhouse, 2010; Howard, 2010). Moreover, research on how English as Foreign Language (EFL) is taught to foreigners living in USA and UK is overwhelming (Ortiz et al., 2011; Safford \& Drury, 2013; Li \& Walsh, 2012; Fysh, 1990; Palmer, 2011; Parkes \& Ruth, 2011; Hashimoto \& Lee, 2011; Mumin, 2011; Simon \& Taverniers, 2011; Johnson, 2012; Dubetz \& de Jong, 2011). Much in the above and other existing literature focuses on how native and non-native teachers carry out ELT and EFL in the English setting. Moreover the literature focuses on teaching English as a subject.

Due to colonial history, the global mobility and internationalisation of English language, many settings outside USA and UK have adopted English as their medium. It eases interaction in official settings, public places, and generally communication beyond local settings. In the academia, Higher Education is the peak level at which a person is assisted to gain expertise in a field interest. At a point in time during this process, students are required to undertake a practicum to try out their expertise. It becomes necessary that a uniting medium is commonly used in interacting with stakeholders and other persons during the internship.

The education sector which enrols many University students on practicum, adopted English as a medium for instruction (Government White Paper on the Education, 1992) in order to accommodate students from diverse local backgrounds. Little attention has been put on teachers to whom English is a Second Language (ESL) and using it as a medium to teach learners whose first language is also other than English. This is the main focus for this article. The common claim is that ESL teachers fail to get meanings across to ESL learners due to limitedness in the foreign medium, which indirectly suggests using local languages as education media even at Higher Education. My major assumption is that student-teachers' linguistic choice of vocabulary and phraseology is not due to that limitedness but depends on their beliefs about their learners and the learning situation.

\section{Beliefs and Practice}

Beliefs are understood differently, but commonly referred to as convictions, opinions, perceptions, or positional grounds on an entity, an action or behaviour. Palmer (2011) synonymises beliefs as ideologies or truths consciously or unconsciously cherished by the beholder. Teaching is a complex practice interwoven by beliefs which impact on its process. It is likely that teachers draw on their beliefs during practice rather than "rationally based forms of knowledge" (ibid, 105). Palmer's argument reiterates the assertion by Li and Walsh (2011) that what teachers do and say during their interactions with students is an influence of their beliefs not knowledge. Knowledge is linked to facts. Teachers' expectations of their learners and their entire classroom action, is an effect of their beliefs. Their self-perception as teachers in their professional action is a pointer to their beliefs (Pettit, 2011). Beliefs are personal judgement of the course of action but not objective truths to be followed. While beliefs play an important role in the process of teaching (Gay, 2009 op cit. Hertzog, 2011), teachers' ability to examine their beliefs about certain realities in the learning situation, makes their interaction more successful as far as achieving learning objectives is concerned. This is because, through self-examination some biases disguised as beliefs can be overcome.

Teachers are required to make decisions for their practice. Good decisions create successful learning. Decisions depend on their perception of the learners, learning environment, subject content, teaching approach all of which are influenced by the teachers' beliefs. As Li and Walsh (2011) suggest, the best way to understand and discuss how teachers' beliefs influence their practice is to get down to their work environment where they interact with each other, but mostly with their learners. Teachers' classroom action is wide as it may include, content, language, movement and so on and may be studied by observation, interviews, or other ethnographic approaches. In this article, the main focus is on teachers' beliefs on the classroom medium. 


\section{Language and Teaching}

Learners come from different social backgrounds and meet in a classroom as a space to discuss and make sense of what they learn. The diversity in social background is apparent in ethnic, religious, economic, political and linguistic. Language is central in constructing meaning among diverse interacting persons in classroom (Then \& Ting, 2011; Hertzog, 2011). In other words, as Fysh (1990) opines, language is purposively for sharing, obtaining and giving information, discussing and expressing emotions and opinions.

Teachers bear the primary duty in how to use language in an interactive (teaching and learning) situation. The clearer they are in their language, the easier it is for a student to construct meaning during learning. In teaching, students and teachers engage in various clarifying behaviours like asking questions, explaining in order to negotiate meaning in the classroom ( $\mathrm{Li}$ et al., 2011). Therefore, it is incumbent on the teachers to use language well. Language use in this sense goes beyond "linguistic competence" to "communicative competence" (Hymes, 1972, op. cit. Safford \& Drury, 2013). This does not mean that language proficiency is not necessary. Li et al. list "language incompetence such as foreign accents, poor grammar" as labels of teacher failure in communication. On the contrary, teacher's command of language medium plays a central role in their success as classroom teachers. Hume's "communicative competence", asks for coupling grammatical competence with competent knowledge of subject content.

In Uganda, adopting English as a medium of instruction called proficiency and fluency for teachers whose first language is not English; and for students who also do not have English as their first language, challenged their ability to comprehend what is said in English. This however, rarely crosses minds that such policy affects pedagogy. I agree with Laoire (2012) that it is in the classroom that policy is played out. Teachers have to practice within the limits of the policy to interact with learners but without alienating them from their social, cultural and linguistic feelings and belongingness. This is where beliefs come to control the teachers' actions in classroom. Garton (2012: p. 29) underlines "asymmetrical role relationship between teachers and learners" evidently displayed in choosing what to emphasise in teaching, how to emphasise it, what to ask, how to ask, when to ask, and at times who to respond. From an outsider perspective, for example, one may take teachers' unfinished utterances as poor language proficiency but, as Martin (1999, op cit. Then \& Ting, 2011: p. 300) finds, unfinished utterances are "often predictable and completed by students' chorus response $\cdots$ suggesting that a common understanding between students and their teacher was achieved". It is the teachers' belief that prompts them to use unfinished utterances during interaction.

The role of any teacher in an interactive situation with students should be to assist them think critically and act independently. As Wertsch (1985) suggests, the teacher and student are committed to a mind shared through language. Language in interactive direct encounters takes mainly, descriptive, explanatory, exclamatory and interrogative forms. But of them, only interrogative form can enable the teacher to ascertain whether the students appreciate the encounter. This justifies my focus on interrogative language during classroom interaction and teachers' beliefs embedded.

\section{Classroom Questioning}

Interrogatives are those statements that elicit response. In this sense there are explicit questions that begin with "wh-" and "h" which obviously elicit response from the questioned (Burbules, 1993; Sinclair \& Coulthard, 1975). Implicit ("wh-") questions are on the other hand not obvious and identified by intonation, i.e. variation of voice sound over speech utterances (May, 1988). Some researchers (Gee, 1999; Dillon, 1990) suggest that intonation plays a big role in good questioning when it supports the intent of the question. Intonation is part of the linguistic knowledge because it marks differences where ambiguities would occur in written language. As Moran (2002) suggests, intonation can hardly be independent of prominence, pitch and so forth. Prominence given to the word tends to be associated with its particular importance in the statement. This means that it is the speaker's choice to give prominence to one particular word rather than another. However, intonation varies according to contexts, and thus prominence and pitch are context dependent. Furthermore, in a question, pitch tends to be higher than in an explanatory statement. Brazil (1985 op cit. Hewings, 1992) suggests that in most cases, when one selects the rising tone to be used on a word ending a statement, it may imply that they assume that the listeners share a common ground on the particular point being explained. Agreeing with research done by Cangelosi (1988) and Coulthard (1992), I aver that the tone, which indicates sharing common ground on a particular point, may commonly be interpreted by listeners as eliciting a response from them. 


\section{Method}

I carried out qualitatively based research with four University students on teaching practicum in two secondary schools in Uganda. Their pseudonyms and other details are shown in the Table 1.

In the subject field, choosing two student-teachers in science and two in arts was based on assumption that the content, pedagogy, and thought processes in one field differ from another field. This may dictate the nature of interrogatives during interaction. Observing three teaching hours per student-teacher at different time of day and in different year group enabled to validate my study conclusions.

From the gender perspective, the choice of male and female in each school was based on the assumption that men's actions may differ from women's actions in similar or even same situations due to generic make up. This may also be reflected in the interrogatives despite sharing the same subject field.

Student-teachers have to do the first practicum at the end of the second academic year, and the second at the end of the third academic year. The practicum experience in teaching was assumed a possible contributory factor to student-teachers' interrogatory approach. I opted to work with individuals of different experiences basing on assumption that it may dictate the type of interrogative approach.

\subsection{Observation}

Using this method I observed the situation under which teachers interacted with their learners and with their consent I tape-recorded student-teachers' interactions with learners. The intention was to get a true count of the number and nature of questions used. Therefore, I categorised teacher's questions as:

Closed Questions (CQ): Researchers (e.g. Tsui, 1995; MacKay, 1995; Dillon, 1990) refer to this type of question as solicitous of a yes/no response or it requires student to recall already acquired knowledge and provide a specific response.

Open Questions (OQ): The open category refers to questions that are meant to seek detailed information, and allow the respondent to contribute their views with personally chosen words (Dillon, 1990; Krueger, 1988).

Chorus Answer Questions (CAQ): This style takes the form of word(s) completers. It is identified by a teacher's rising intonation at the end of a statement in various ways (Kress \& Hodge, 1979):

- Ending an utterance with a half spoken word in a rising intonation provoking students to complete, e.g. "Living beings need oxgy $\cdots$ ?"

- Repeating the just uttered phrase but replacing the last word with an interrogative in a rising intonation provoking students to say the last word, e.g. "We eat to live. To what?"

- Uttering a statement but ending with a rising intonation that provokes students to fill in the missing last word, e.g. "The Second World War was started by *??"

- Uttering a statement but ending with an interrogative uttered in a rising intonation that provokes students to insert the right word, e.g. "Religion and formal education were both brought by whom?"

- Directly seeking for attention, e.g. "Are we together?", "Do you get me?", "Are you following?"

This type of approach indirectly attracts students to answer in a chorus way, hence the name, chorus answer question.

The details in Table 2 show the number of question types and totals applied by each student-teacher in every hour I observed.

\subsubsection{Nature of Questioning and Characteristic}

\section{1) Gender}

Based on the data in Table 2, Figure 1 and Figure 2 make it apparent that male student-teachers used Chorus answer questions at a difference of 6\% more than the female student-teachers who also used Closed Questions at a difference of $6 \%$ more than the male student-teachers. These Figures suggest some little significant differences which indicate that the males during my research involved students more in shorter memory than the females. However, it is important to note that the percentages of either gender in occupying learners with CAQ and CQ are significantly higher than the percentage of OQ usage which is only $5 \%$. I will discuss this implication later in the general questioning tendency.

2) Experience

The Figures for experience are the same as those for gender since both females happen to be of second practicum experience and both males of first practicum experience. Figure 1 and Figure 2 indicate that teachers 
Table 1. Teacher's characteristics.

\begin{tabular}{cccc}
\hline Name & Gender & Practicum experience & Subject field \\
\hline Julia & Female & 02 & Biology \\
Jack & Male & 01 & History \\
Mona & Female & 02 & Geography \\
Jerry & Male & 01 & Chemistry \\
\hline
\end{tabular}

Table 2. Student-teacher's nature of questioning.

\begin{tabular}{|cccccccccccccccccccc}
\hline \multicolumn{1}{c}{ Teacher } & \multicolumn{1}{c}{ First hour } & \multicolumn{1}{c}{ Second hour } & \multicolumn{1}{c}{ Third hour } \\
\hline Name & $\begin{array}{c}\text { Subject } \\
\text { field }\end{array}$ & $\begin{array}{c}\text { Year } \\
\text { group }\end{array}$ & CAQ & CQ & OQ & Total & $\begin{array}{c}\text { Year } \\
\text { group }\end{array}$ & CAQ & CQ & OQ & Total & $\begin{array}{c}\text { Year } \\
\text { group }\end{array}$ & CAQ & CQ & OQ & Total & total \\
\hline Julia & Science & 3 & 04 & 20 & 04 & 28 & 2 & 08 & 13 & 02 & 23 & 1 & 10 & 15 & 01 & 26 & 77 \\
Jack & Arts & 2 & 15 & 16 & 01 & 32 & 1 & 09 & 09 & 01 & 19 & 3 & 06 & 08 & 02 & 16 & 67 \\
Mona & Arts & 1 & 18 & 18 & 00 & 36 & 2 & 13 & 16 & 02 & 31 & 3 & 24 & 16 & 00 & 40 & 107 \\
Jerry & Science & 2 & 25 & 10 & 00 & 35 & 3 & 19 & 26 & 00 & 45 & 1 & 15 & 17 & 05 & 37 & 117 \\
TOTAL & & & 62 & 64 & 05 & & & 49 & 64 & 05 & & & 55 & 56 & 08 & 368 \\
\hline
\end{tabular}

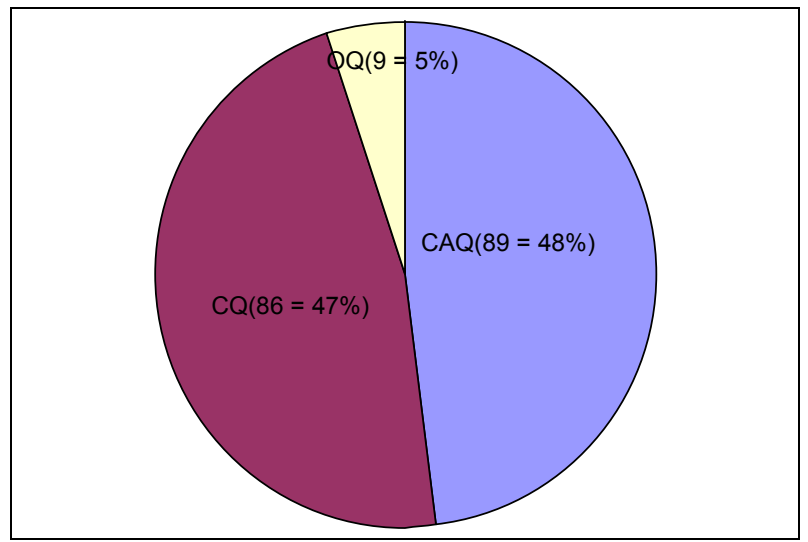

Figure 1. Showing the questioning tendency by male studentteachers (Jack and Jerry).

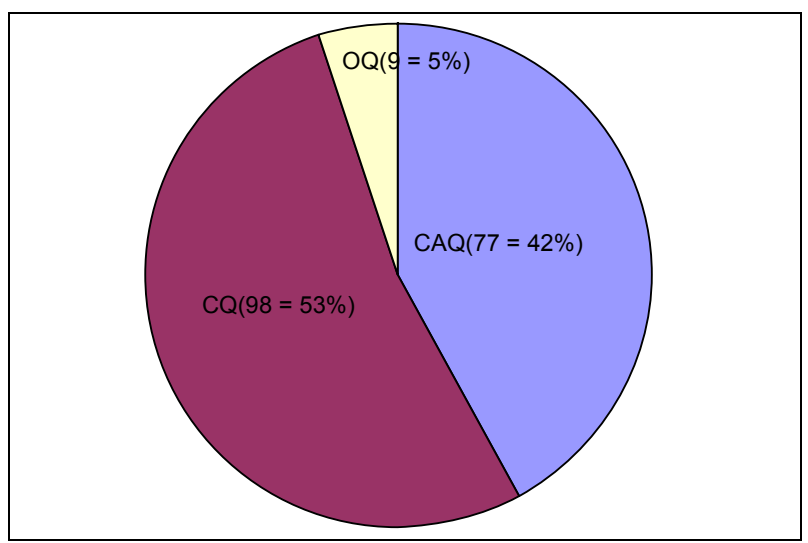

Figure 2. Showing the questioning tendency by females (Julia and Mona). 
with first practicum experience used Chorus Answer Questions at a difference of 6\% more than the teachers with second practicum experience who also used Closed Questions at a difference of 6\% more than those with first practicum experience. These Figures specify some little significant differences which indicate that the studentteachers with first practicum teaching experience during my research involved students more in shorter memory than the student-teachers with second practicum experience. However, it is important to note that the percentages of either stage of experience in occupying learners with CAQ and CQ are significantly higher than the percentage of OQ usage which is only $5 \%$. This implication will be discussed later.

3) Subject field

Figure 3 and Figure 4 indicate that that the Arts student-teachers used Chorus Answer Questions at a difference of 7\% more than the Science student-teachers who also used more Closed Questions at a difference of 4\% more than the Arts student-teachers.

The conclusions here seem to tally with those drawn for gender and experience, namely; the Arts studentteachers involved learners more in shorter memory than the Science student-teachers who involved learners in deeper thinking slightly more than the Arts student-teachers at a difference of $3 \%$. However, it is important to note that the percentages of either subject field in occupying learners with CAQ and CQ are significantly higher than the percentage of OQ usage which is only $6 \%$ for Science and 3\% for Arts as I will discuss in the next section.

\subsubsection{The General Questioning Tendency}

While all the above Figures and conclusions may point to tendencies in using a type of questioning approach which differ according to gender, experience and subject, I wish to focus more on the general questioning tendency as presented in Figure 5. The data in the Figure indicate a general questioning tendency that persisted in the two colleges at the time of this research, used by the four student-teachers that participated in my study.

The Figure indicates a higher tendency in using Closed Questions (50\%), a high tendency in using Chorus Answer Questions (45\%), and very minimal tendency in using Open Questions (5\%) during the time of observation. Although these findings are not for generalised purposes, I have to underline that these tendencies could be persistently used by these student-teachers, or in these schools, and maybe in other schools in Uganda.

\subsection{Focused Interviews}

Student-teachers were committed to interview sessions whereby I focused on particular questions and questioning approaches during their interactions. In their responses I managed to obtain their beliefs in choosing particular questions for their classroom interactions.

\subsubsection{Open Questions}

In the focused interviews, Julia said that her reason for using this type of question was to help "the students to get used to thinking on their own instead of giving them questions that require clear-cut answers." Julia believed

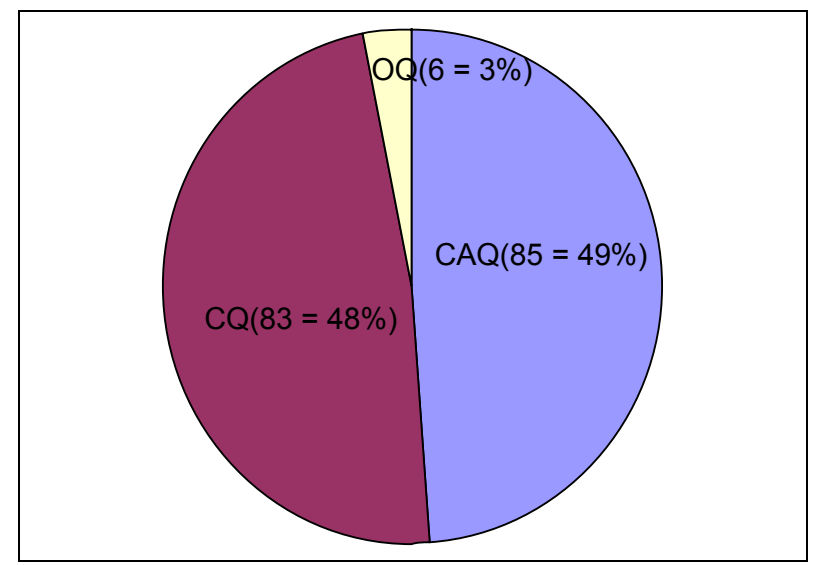

Figure 3. Showing the questioning tendency by arts studentteachers (Jack and Mona). 


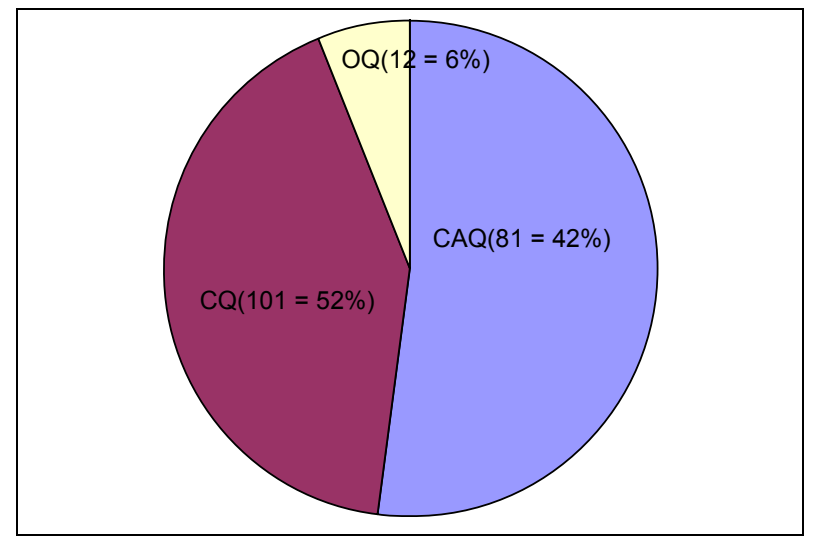

Figure 4. Showing the questioning tendency by science student-teachers (Julia and Jerry).

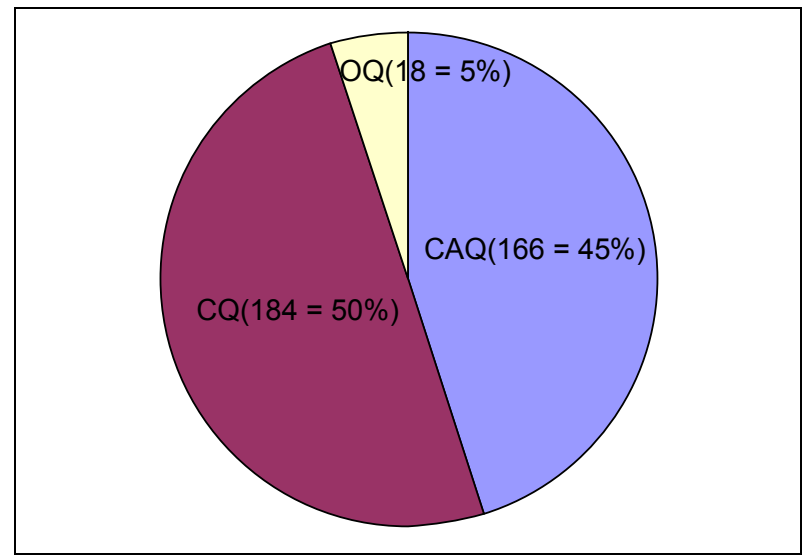

Figure 5. Showing the general questioning tendency.

that this empowers the students in their learning. For example, whenever Julia used questions like "What is a pest?" she always wished to give the students opportunity to control their learning because she trusted that they too have knowledge according to their various experiences. She therefore said, "I do not expect a specific answer because the learners have different experiences of pests some of which I do not know. This could easily stick to their minds." Jack shared a similar interpretation. He perceived thinking as an acquired value. Therefore, his belief in using the open questions was to make the learners "use their thinking so far acquired so as to contribute freely" to the classroom interaction. With a slightly different understanding, Mona looked at these questions as a means to sustaining the teacher-learner relationship because learners are likely to enjoy the lesson if they participated with deeper thinking compared to the other teacher-dominated approaches where "the child simply listens instead of thinking". However, she believed that this interaction could only be possible if:

$\cdots$ the topic is within the learner's realm of understanding that he can think out for himself the response. $\cdots$ It allows you to interact when the learner takes the greater part because he is very competent of the environment.

Since open questions contribute to the learner's development of deeper thinking, Jerry too was certain that they "bring critical thinking and help the learner to have an autonomous response. If the learner can respond critically, it implies that he could apply that knowledge elsewhere." Therefore, the four participants seemed to agree that the thinking provokers help to sharpen the learner's mind and encourage the learner to participate in learning in a more interactive way.

On the other hand, some student-teachers held a belief that the nature of questioning could be determined by the available time for the lesson. This is based on the response made by Jack for using few open questions. He said that he avoided the open questions because "they require much time to respond to them". 


\subsubsection{Chorus Answer Questions}

Every participant assented that the main intention for this questioning approach was to aid in managing the attention of the learners. Julia acknowledged that she used chorus answer questions in the form of completers just as one would use them directly because they help "to capture learners' attention just as one would ask 'Are you following?" In these questions, Julia intended to see "whether the learners are together with their teacher". Similarly, Jerry saw the "capturing" role of this style as helping to maintain learners" attention and "to awake the sleepers and those who are absent-minded".

In slightly different terms, Jack viewed chorus answer questions as performing the "attractive" role. Unlike Julia's intention to "capture", Jack sounded like he intended to motivate learners to pay attention. Jack enjoyed using this approach for attracting learners' attention because most of "these lessons are done in the afternoon, and therefore they need much motivation. If the learners are tired they can be re-strengthened." For example, Jack was convinced that in the question, "Williams organised the people to struggle against the what?" he intended to make the learners "to complete so that even the one who had been dozing or not following may catch up and know that whenever we talk of Williams, we have to attach him to Africanism." He clarified that in his classroom encounters such questions tended to come "after spending a long period of explanation. After sometime I may ask the learners whether they are together with me $\cdots$ in order to attract the absent minded learners, and get their attention."

On the contrary, Mona initially refused to acknowledge the academic importance of the chorus answer questions and claimed that, "it is a poor and a forbidden method of questioning." This claim is contrary to Jerry's assertion. Jerry was certain that the training advises teachers to use chorus answer questions in the form of completers, but with a caution that, "they should not dominate because one can think that all students have understood whereas in the process of chorusing a completion, others may be completely lost." Regardless of who holds the right ground on the legitimacy of the style, I realised that Mona too had the "capture" intention. Mona claimed that if "you see that the learners are absent-minded, you can use such questions to bring them back."

Furthermore, Jerry used chorus answer questions for a number of additional intentions. He said that when he gave a question that required the learners to repeat the word at times he intended "the learners to pronounce well the words". In addition, Jerry believed that "in the lesson there are some weak students". Therefore, whenever he gave an attention seeker, which obviously provoked a chorus answer, he expected that these weak learners might:

$\cdots$ get a chance of chorusing with others, they will feel that they have done something. Some of them [students] fear to stand on their own. With time, this completion may give such learners some confidence to talk on their own. It can as well encourage the slow and quick learners to follow the lesson together in order to achieve the lesson objectives.

In the focused interviews with Julia and Jack, I realised that time could be one of the factors for using chorus answer questions. Julia indirectly claimed that these questions have a time-saving purpose because, "the time is too little for the quantity of the content which is new and cannot be repeated any time." Jack also shared the belief that chorus answer questions save time because "we have got an overloaded curriculum; due to new subjects and content, time becomes more limited. So we are at times forced to economise time in that way."

\subsubsection{Closed Questions}

Generally, Jack, Jerry and Mona revealed that they used closed questions with the intention of helping the learners to retrieve knowledge acquired in and/or outside the classroom. Jack clarified that in the question, "In which party was Milton Obote at the time of Independence?" he desired "to know whether they [students] know that history of P5" as well as the history of their country. Jack looked at this approach as a good starting point to determine what the learners know and what they do not know. Jack believed that the ability to recall the acquired knowledge also helps the learners to transfer knowledge by relating the current "topic with the one we might have seen earlier". Jerry shared a similar thinking that closed questions make the learner remember things. He said:

They help the learner to try practising what the teacher teaches in order to remember the next time the teacher questions him. Even in our learning from first to third term, if the learner has not remembered, he may not be able to pass exams. That is why I try to encourage them to keep recalling. 
It is this idea of helping the learner to retrieve the acquired knowledge that Mona based her claim on, that, closed questions play the role of "concretising the matter into the learner's mind". She argued that although the closed questions may result in the child parroting the content by encouraging "cram work", on the other hand they help the learner to think to some degree. Because of the student's mental operation involved in the system of retrieving the retained knowledge, Mona was conscious of the different levels of thinking abilities her learners may have and therefore she felt that when she gave these questions she intended to level-out these ability differences because:

$\cdots$ if their understanding is low, you can't give them the thinking questions $\cdots$ In the classroom we have learners who understand quickly, others take long, and others take longer $\cdots$ therefore, I use questions of

this type that can be accommodated by their different levels of understanding.

In addition, Julia shared the uncertainty about the student's mental abilities. She said that she used this questioning approach simply to test students' knowledge because, "according to their [learners'] age, their reasoning is a bit low. They cannot manage to give detailed answers." Although we could make a distinction between knowledge and understanding, Julia's assertion reflects her intention of posing questions which match with the learners' level of ability in knowledge production. Jack was rather more direct concerning his intention of using closed questions in consideration of learners' level of ability in knowledge production. He said that, "you bring a question, phrase it and give it to them, and then you control their response" because, for Jack, controlling the response meant obtaining answers relevant to the topic as outlined in the curriculum. Jack expressed more confidence about using closed questions than other styles. He uses closed questions as a mechanism of classroom management; for he said that, he could not allow questions that provoke "learners to discuss among themselves because I can lose the classroom control. They begin to argue among themselves, which could produce chaos. The best way is to use this type which requires them to recall knowledge."

\section{Discussion}

This study was carried out in two rural schools in the central region of Uganda mainly dominated by Bantu people. Among the Bantu, elders are regarded as custodians of knowledge. This is apparent in the practices, norms, proverbs and idioms that caution the young to listen to the elders and take their knowledge whole sale. Free expression is according to age and status. Queries from the elders to the young, commonly call for yes/no/I don't know response or recalling a certain fact. Since culture shapes people's beliefs, it could crop into their practices also. Thus it may be a contributory factor to the teachers' tendency in using more CQ and CAQ than OQ when interacting with students.

Nevertheless, it could be that the content for teaching does not lend itself easily to using OQ than other approaches. Some content could be difficult for student-teachers to internalise easily and transform into questions that would challenge learners to exercise their thinking capacity in depth. There could also be a possibility that the content is too much to be taught in the available time. This may also shape student-teachers' belief in using time-saving approaches that do not allow learners to use much time in responding. The OQ type that requires more time to think becomes minimally used.

Moreover, the existing policies and teaching conditions sometimes may also contribute to shaping beliefs on the nature of questioning approach. While OQ would allow learners to think out a response which could be given by an individual, it may not be as involving as the CQ and CAQ. Chorus Answer Questions, for example, tend to attract chorus answers as the name suggests. The chorus response may involve more learners than OQ although the level of rational participation remains questionable. For example, classroom population sizes may affect the nature of questioning. A 1:200 (teacher-learner) ratio may make the teacher feel disgusted than a 1:40 ratio. While the former may provoke a feeling of teaching to get the content out of the way, using CAQ to keep learners on interactive track, the latter may stimulate teacher's enjoyment of the interaction punctuated by learner involvement through responding to OQ. I do not deny that the opposite can't be possible, but that there is a more likely tendency.

\section{Conclusion}

In this paper I have focused on student-teachers whose first language is not English, but using the English medium to interact with learners also whose first language is other than English. The article was aiming at studying 
student-teachers' beliefs as the key influence to using a type of language expression. Focusing on questioning as one of the school room forms of linguistic interaction a person who practices in situations where the medium is as well the learners' and the teachers' first language may regard the dominance of CQ and CAQ in the opposite situations as teacher's limitedness in language proficiency. However, I have drawn on student-teachers practicum and voices on the nature of questions posed in classroom to discuss that it is less a shortfall of language proficiency than teachers' beliefs that prompt a linguistic utterance. Culture, education policies, the curriculum, existing interactive situation all shape the nature of beliefs harboured by teachers which instead influence their teacher-learner interactions.

\section{References}

Batalova, J., \& Fix, M. (2010). A Profile of Limited English Proficient Adult Immigrants. Peabody Journal of Education, 85, 511-534. http://dx.doi.org/10.1080/0161956X.2010.518050

Baurain, B. (2011). Morality, Relationality, and Listening Pedagogy in Language Education. International Journal of Listening, 25, 161-177. http://dx.doi.org/10.1080/10904018.2011.604604

Burbules, N. C. (1993). Dialogue in Teaching: Theory and Practice. London: Teachers College Press.

Cangelosi, S. J. (1988). Classroom Management Strategies: Gaining and Maintaining Students' Cooperation. New York: Longman Inc.

Coulthard, M. (Ed.) (1992). Advances in Spoken Discourse Analysis. London: Routledge.

Dillon, J. T. (1990). The Practice of Questioning. London: Routledge.

Dubetz, N. E., \& de Jong, E. J. (2011). Teacher Advocacy in Bilingual Programs. Bilingual Research Journal: The Journal of the National Association for Bilingual Education, 34, 248-262.

Fysh, M. C. (1990). An Investigation into Methods of Developing Oral Fluency in Foreign Language Teaching. The Vocational Aspect of Education, 42, 19-23. http://dx.doi.org/10.1080/13636829008619466

Garton, S. (2012). Speaking out of Turn? Taking the Initiative in Teacher-Fronted Classroom Interaction. Classroom Discourse, 3, 29-45. http://dx.doi.org/10.1080/19463014.2012.666022

Gee, J. P. (1999). An Introduction to Discourse Analysis: Theory and Method. London: Routledge.

Government White Paper on the Education (1992). Education for National Integration and Development. Kampala.

Hashimoto, K., \& Lee, J. S. (2011). Heritage-Language Literacy Practices: A Case Study of Three Japanese American Families. Bilingual Research Journal: The Journal of the National Association for Bilingual Education, 34, 161-184.

Helfrich, S. R., \& Bosh, A. J. (2011). Teaching English Language Learners: Strategies for Overcoming Barriers. The Educational Forum, 75, 260-270. http://dx.doi.org/10.1080/00131725.2011.578459

Hertzog, L. (2011). Can a Successful ESL Teacher Hold Deficit Beliefs of Her Students' Home Languages and Cultures? Multicultural Perspectives, 13, 197-204. http://dx.doi.org/10.1080/15210960.2011.616829

Hewings, M. (1992). Intonation and Feedback in the EFL Classroom. In: M. Coulthard (Ed.), Advances in Spoken Discourse Analysis ( pp. 183-196). London: Routledge.

Howard, A. (2010). Is There Such a Thing as a Typical Language Lesson? Classroom Discourse, 1, 82-100. http://dx.doi.org/10.1080/19463011003750699

Johnson, F. L. (2012). Rhetorical Positioning of US Policy Statements about Multilingual Education-With Reference to the EU. Language, Culture and Curriculum, 25, 73-87. http://dx.doi.org/10.1080/07908318.2011.653059

Kress, G., \& Hodge, R. (1979). Language as Ideology. London: Routledge and Kegan Paul.

Laoire, M. (2012). Language Policy and Minority Language Education in Ireland: Re-Exploring the Issues. Language, Culture and Curriculum, 25, 17-25. http://dx.doi.org/10.1080/07908318.2011.653055

Li, L, Mazer, J. P., \& Ju, R. (2011). Resolving International Teaching Assistant Language Inadequacy through Dialogue: Challenges and Opportunities for Clarity and Credibility. Communication Education, 60, 461-478. http://dx.doi.org/10.1080/03634523.2011.565352

Li, L., \& Walsh, S. (2011). 'Seeing Is Believing': Looking at EFL Teachers' Beliefs through Classroom Interaction. Classroom Discourse, 2, 39-57. http://dx.doi.org/10.1080/19463014.2011.562657

MacKay, I. (1995). Asking Questions (2nd ed.). London: Institute of Personnel and Development.

May, R. P. (1988). Confidence in the Classroom: Realistic Encouragement for Teachers. Leicester: Inter-Varsity Press.

Moran, C. (2002). Discourse and Intonation. In: P. Alonso, M. J. Sanchez, J. Hyde, \& C. Moran (Eds.), Aspects of Discourse Analysis (pp. 191-204). Salamanca: Imprenta Calatrava Sociedad Cooperativa. 
Mumin, Z. (2011). Language and Literacy Development in Bilingual Settings. International Journal of Bilingual Education and Bilingualism, 14, 772-775. http://dx.doi.org/10.1080/13670050.2011.576530

Nag, S., \& Snowling, M. J. (2012). Reading in an Alphasyllabary: Implications for a Language Universal Theory of Learning to Read. Scientific Studies of Reading, 16, 404-423. http://dx.doi.org/10.1080/10888438.2011.576352

Ortiz, A. A., Robertson, P. M., Wilkinson, C. Y., Liu, Y., McGhee, B. D., \& Kushner, M. I. (2011). The Role of Bilingual Education Teachers in Preventing Inappropriate Referrals of ELLs to Special Education: Implications for Response to Intervention. Bilingual Research Journal: The Journal of the National Association for Bilingual Education, 34, 316-333.

Palmer, D. (2011). The Discourse of Transition: Teachers' Language Ideologies within Transitional Bilingual Education Programs. International Multilingual Research Journal, 5, 103-122. http://dx.doi.org/10.1080/19313152.2011.594019

Parkes, J., \& Ruth, T. (2011). How Satisfied Are Parents of Students in Dual Language Education Programs?: 'Me parece maravillosa la gran oportunidad que le están dando a estos niños'. International Journal of Bilingual Education and Bilingualism, 14, 701-718. http://dx.doi.org/10.1080/13670050.2011.577762

Peercy, M. M. (2011). Preparing English Language Learners for the Mainstream: Academic Language and Literacy Practices in Two Junior High School ESL Classrooms. Reading \& Writing Quarterly: Overcoming Learning Difficulties, 27, 324362. http://dx.doi.org/10.1080/10573569.2011.596105

Pettit, S. K. (2011). Teachers' Beliefs about English Language Learners in the Mainstream Classroom: A Review of the Literature. International Multilingual Research Journal, 5, 123-147. http://dx.doi.org/10.1080/19313152.2011.594357

Safford, K., \& Drury, R. (2013). The "Problem" of Bilingual Children in Educational Settings: Policy and Research in England. Language and Education, 27, 70-81. http://dx.doi.org/10.1080/09500782.2012.685177

Seedhouse, P. (2010). Locusts, Snowflakes and Recasts: Complexity Theory and Spoken Interaction. Classroom Discourse, 1, 4-24. http://dx.doi.org/10.1080/19463011003750624

Simon, E., \& Taverniers, M. (2011). Advanced EFL Learners' Beliefs about Language Learning and Teaching: A Comparison between Grammar, Pronunciation, and Vocabulary. English Studies, 92, 896-922. http://dx.doi.org/10.1080/0013838X.2011.604578

Sinclair, J. M., \& Coulthard, R. M. (1975). Towards an Analysis of Discourse: The English Used by Teachers and Pupils. London: Oxford University Press.

Taboada, A., \& Rutherford, V. (2011). Developing Reading Comprehension and Academic Vocabulary for English Language Learners through Science Content: A Formative Experiment. Reading Psychology, 32, 113-157.

http://dx.doi.org/10.1080/02702711003604468

Then, D. C. O., \& Ting, S. H. (2011). Code-Switching in English and Science Classrooms: More than Translation. International Journal of Multilingualism, 8, 299-323. http://dx.doi.org/10.1080/14790718.2011.577777

Tsui, A. B. M. (1995). Introducing Classroom Interaction. London: Penguin.

Wertsch, V. J. (1985). Vygotsky and the Social Formation of the Mind. London: Havard University Press. 